\title{
Bacterial handling under the influence of non-uniform electric fields: dielectrophoretic and electrohydrodynamic effects
}

\author{
FLAVIO H. FERNÁNDEZ-MORALES ${ }^{1}$, JULIO E. DUARTE ${ }^{1}$ and JOSEP SAMITIER-MARTí ${ }^{2}$ \\ ${ }^{1}$ Grupo de Energía y Aplicación de Nuevas Tecnologías (GEANT), Seccional Duitama \\ Universidad Pedagógica y Tecnológica de Colombia, Carrera 18, Calle 22, Duitama, Boyacá, Colombia \\ ${ }^{2}$ Departamento de Electrónica, Universidad de Barcelona, c./ Martí i Franqués 1, 08028, Barcelona, España \\ Manuscript received on June 19, 2007; accepted for publication on August 18, 2008; \\ presented by LUIZ DAVIDOVICH
}

\begin{abstract}
This paper describes the modeling and experimental verification of a castellated microelectrode array intended to handle biocells, based on common dielectrophoresis. The proposed microsystem was developed employing platinum electrodes deposited by lift-off, silicon micromachining, and photoresin patterning techniques. Having fabricated the microdevice it was tested employing Escherichia coli as bioparticle model. Positive dielectrophoresis could be verified with the selected cells for frequencies above $100 \mathrm{kHz}$, and electrohydrodynamic effects were observed as the dominant phenomena when working at lower frequencies. As a result, negative dielectrophoresis could not be observed because its occurrence overlaps with electrohydrodynamic effects; i.e. the viscous drag force acting on the particles is greater than the dielectrophoretic force at frequencies where negative dielectrophoresis should occur. The experiments illustrate the convenience of this kind of microdevices to microhandling biological objects, opening the possibility for using these microarrays with other bioparticles. Additionally, liquid motion as a result of electrohydrodynamic effects must be taken into account when designing bioparticle micromanipulators, and could be used as mechanism to clean the electrode surfaces, that is one of the most important problems related to this kind of devices.
\end{abstract}

Key words: dielectrophoresis, electrohydrodynamic effects, biochips, bacterial handling.

\section{INTRODUCTION}

Handling of biological objects constitutes an important operation in many biotechnological processes such as biochemical assays, biocell detection and separation, cell fusion and gene manipulation (Hoettges et al. 2003, Figeys and Pinto 2000, Lee and Tai 1999). In conventional techniques, cells are often treated as a mass in the form of suspensions in a liquid medium. However, cells have dimensions in the order of microns and are usually fragile, and mechanical components commonly employed to perform this handling are too large and stiff (Sato et al. 1990).

Correspondence to: Flavio Humberto Fernández-Morales E-mail: flaviofm1@gmail.com
Diverse non-contact techniques have been proposed using electric, magnetic, ultrasonic and optical forces as the actuation mechanism to handle and characterize biological cells (Choi et al. 1999, Fuhr et al. 1998a, Porras et al. 2004). Among these alternatives, electrostatic fields are the most suitable for miniaturization because they do not have mechanical moving parts, and only a few electrodes have to be fabricated (Fuhr and Shirley 1998).

Electric fields involve two phenomena. The first one is electrophoresis that uses direct current voltages to achieve migration of charged particles in a solution, and special precautions must be taken against electrolytic dissociation that might take place at the electrodesolution interface (Webster and Mastrangelo 1997). The 
second one is dielectrophoresis, DEP, that is more suitable because dissociation is prevented using high-frequency signals.

DEP was a term first used by Pohl in 1951 in order to describe motion of electrical neutral matter caused by its interaction with non-uniform electric fields (Pohl 1951). This phenomenon has been employed in applications such as: artificial-particle and bioparticle characterization (Burt et al. 1990), devices for cell fusion (Lee et al. 1995), particle separation based on its differential polarizability (Gascoyne et al. 1997), particle collection and patterning (Velev and Kaler 1999, Rosenthel and Voldman 2005), cellular culture over a field-protected electrode surface (Fuhr and Wagner 1994) and particle handling in terms of linear motion and positioning (Wang et al. 1997), levitation (Kaler and Pohl 1983), and trapping in electric-field cages (Fuhr et al. 1998b).

In the past 25 years lots of engineering work has been invested to develop bioparticle microhandling microtools, that implies the fabrication of devices whose size roughly matches that of the bioparticle itself, normally between 1 to $100 \mu \mathrm{m}$ or less if virus or macromolecules must be handled. Nowadays these sizes and resolution levels may only be achieved using microsystems technology that suits very well the requirements of miniaturized microstructures aimed to handle biological objects in order to obtain more confident, faster and cheaper biochemical assays (Reimer et al. 1995). Besides diverse materials and technological approaches have been used to fabricate these microtools, silicon substrates with electrodes made in noble metals are usually employed to manufacture such devices (Pethig et al. 1998, Schnelle et al. 1996).

This paper describes the modeling and experimental verification of a castellated microelectrode array intended to handle biocells, based on common dielectrophoresis. The proposed microsystem was developed employing platinum electrodes deposited by lift-off, silicon micromachining, and photoresin patterning techniques. Having fabricated the microdevice it was tested employing Escherichia coli as bioparticle model.

Positive DEP could be verified with the selected cells for frequencies above $100 \mathrm{kHz}$ but for lower values the particle behavior could not be explained by the classical dielectrophoretic theory. In other words, negative
DEP could not be experimentally verified because electrohydrodynamic effects, usually unconsidered, were observed as the dominant phenomena when working at lower frequencies. It shows that the liquid motion as a result of electrohydrodynamic effects must be taken into account when designing bioparticle micromanipulators, and could be used as mechanism to clean the electrode surfaces, that is one of the most important problems related to this kind of devices. The most relevant results as well as the basic phenomena involved in microhandling of bacteria by means of non-uniform electric fields are reported underneath.

\section{MATERIALS AND METHODS}

The Dielectrophoretic Force

Dielectrophoresis, DEP, is defined as the lateral motion imparted on uncharged particles as a result of polarization induced by non-uniform electric fields. This motion may be toward or away from the electric field maximum, depending on the electrical properties of the particles and suspending medium, respectively. Such a definition stands for the so-called conventional or common dielectrophoretic (c-DEP) phenomena.

For a non-ideal insulating spherical particle of radius $r$ and relative complex dielectric permittivity $\varepsilon_{p}^{*}$ suspended in a medium of relative complex dielectric permittivity $\varepsilon_{m}^{*}$ and interacting with an electric field of strength $\mathbf{E}$, the time-averaged dielectrophoretic force is given by (Wang et al. 1993):

$$
\mathbf{F}_{\text {DEP }}=2 \pi \varepsilon_{0} \varepsilon_{m} r^{3} \operatorname{Re}\left[\mathrm{F}_{\mathrm{CM}}\right] \nabla|\mathbf{E}|^{2}
$$

where $\varepsilon_{0}=8.854 \times 10^{-12}\left(\right.$ Farad $\left.\mathrm{m}^{-1}\right)$ is the freespace permittivity, $\nabla$ is the gradient operator and $\operatorname{Re}\left[\mathrm{F}_{\mathrm{CM}}\right]$ denotes the real part of the Clausius-Mossotti factor defined by:

$$
\mathrm{F}_{\mathrm{CM}}=\frac{\left(\varepsilon_{p}^{*}-\varepsilon_{m}^{*}\right)}{\left(\varepsilon_{p}^{*}+2 \varepsilon_{m}^{*}\right)} .
$$

The relative complex dielectric permittivity is given by:

$$
\varepsilon^{*}=\varepsilon_{0}^{\varepsilon}-j^{\sigma / \omega}
$$

where $\varepsilon$ is the relative effective permittivity, $\sigma$ is the effective conductivity, $\omega$ is the angular frequency of the applied field and $j=\sqrt{-1}$. 
DEP can be divided into two phenomena, as depicted in Figure 1. The first one is known as positive dielectrophoresis (p-DEP). It is characterized by the particle motion towards the strongest, or maximum, region of the electric field as a consequence of a positive value of the $\mathrm{Re}\left[\mathrm{F}_{\mathrm{CM}}\right]$. $\mathrm{p}$-DEP occurs for particles that are more polarizable than the medium. On the other hand, if the particle polarizability is low enough for the $\operatorname{Re}\left[\mathrm{F}_{\mathrm{CM}}\right]$ to become negative, i.e. when the particle effective permittivity and/or conductivity are smaller than those of the medium, the $\mathbf{F}_{\text {DEP }}$ will tend to move the particle towards the weakest, or minimum, region of the electric field. This phenomenon is called negative dielectrophoresis (n-DEP) (Stephens et al. 1996).

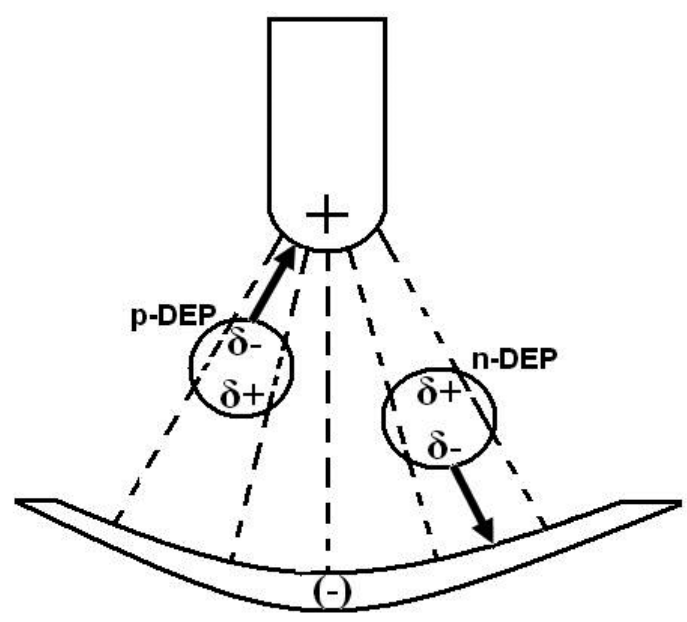

Fig. 1 - Two different particles in a non-uniform electric field. The particle on the left is more polarizable than the surrounding medium and is attracted towards the strong field at the pin electrode (p-DEP), whilst the particle of low polarizability on the right is directed away from the strong field region (n-DEP).

From equation (1) it can be seen that $\mathbf{F}_{\text {DEP }}$ depends on the particle size, as well as on the magnitude of the electric field which is related to the electric potential applied. The gradient operator stands for the spatial nonuniformity of the electric field applied, which is a geometrical factor depending on the electrode layout (Feeley and Pohl 1981). Furthermore, $\mathbf{F}_{\text {DEP }}$ can actuate on both direct and alternating current fields as a consequence of its sign independence of the electric field polarity, justified by the proportionality of the force to the square of the electric field magnitude. In addition, the direction of this dielectrophoretic force depends on the polarity of the induced dipole moment, which in turn is determined by the conductivities and permittivities of the particle and its suspending medium.

Thus, one of the most important parameters that rules DEP is the polarizability function, the so-called Clausius-Mossotti factor, because it establishes the sign of the dielectrophoretic force, i.e. $\mathrm{F}_{\mathrm{CM}}$ determines the occurrence of $\mathrm{p}$-DEP or n-DEP depending on whether $\mathrm{Re}\left[\mathrm{F}_{\mathrm{CM}}\right]$ is positive or negative, respectively.

Equation (2) corresponds to the homogeneous sphere model that can be used with polystyrene microbeads (Arnold et al. 1987). However, when the behavior of cells such as viruses, bacteria or protoplasts must be explained, the single-shell particle model is a better choice. Living cells are usually modeled as a homogeneous, permittivities, spherical particle of radius $r$, having complex permittivity $\varepsilon_{\text {int }}^{*}$, surrounded by a very thin shell corresponding to a membrane of thickness $d$, having complex permittivity $\varepsilon_{\text {mem }}^{*}$, which defines the particle complex permittivity as (Gascoyne et al. 1995):

$$
\varepsilon_{p}^{*}=\varepsilon_{\mathrm{mem}}^{*} \frac{\left(1+\frac{d}{r}\right)^{3}+2\left[\frac{\left(\varepsilon_{\mathrm{int}}^{*}-\varepsilon_{\mathrm{mem}}^{*}\right)}{\left(\varepsilon_{\mathrm{int}}^{*}+2 \varepsilon_{\mathrm{mem}}^{*}\right)}\right]}{\left(1+\frac{d}{r}\right)^{3}-\left[\frac{\left(\varepsilon_{\mathrm{int}}^{*}-\varepsilon_{\mathrm{mem}}^{*}\right)}{\left(\varepsilon_{\mathrm{int}}^{*}+2 \varepsilon_{\mathrm{mem}}^{*}\right)}\right]}
$$

Replacing equation (4) in the expression of the Clausius-Mossotti factor, equation (2), it is possible to obtain further insight into the behavior of bioparticles under the influence of non-uniform electric fields.

\section{The Electric Field Modeling}

Equation (1) shows that $\mathbf{F}_{\text {DEP }}$ depends on three factors: the particle size, the electric properties of particles and medium, and the geometrical inhomogeneities of the electric field $\left(\nabla \mathrm{E}_{\mathrm{RMS}}^{2}\right)$. Furthermore, the last factor hinges on the physical layout of the selected electrodes while the other ones are independent of such electrode considerations. In view of this, it is necessary to evaluate the electric field over the electrode surface.

Calculations presented below correspond to the interdigitated castellated electrode layout depicted in Figure 2. A 3-D model, was studied by means of the commercial program ANSYS (Swanson Analysis Systems, Inc.), which is a general purpose software that 
uses the Finite Element Method (FEM) to solve physical problems (Kohnke 1995).

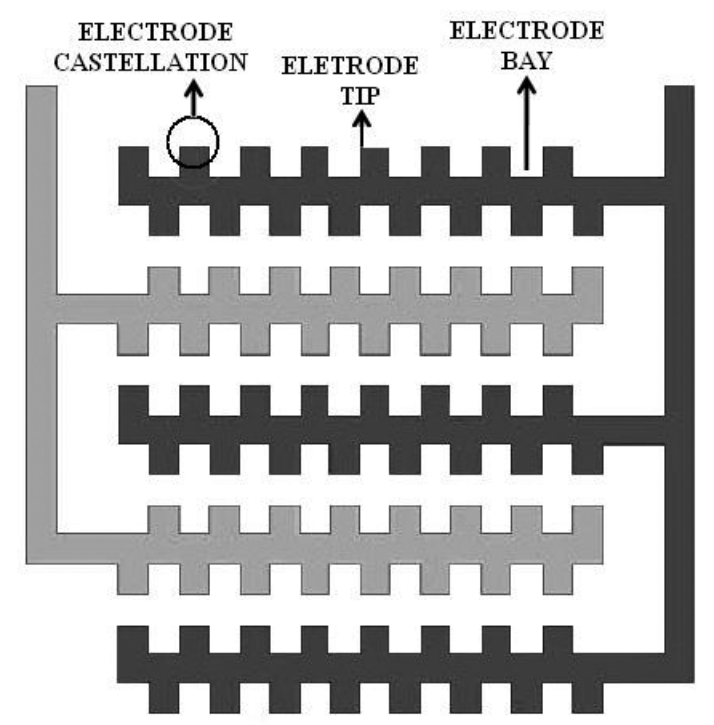

Fig. 2-Classical interdigitated castellated microelectrode pattern, solved by a FEM model with a castellation size and medium height of $50 \mu \mathrm{m}$ and an electrode thickness of $1 \mu \mathrm{m}$.

Having applied a difference potential of $\pm 5 \mathrm{~V}$ and considering the interelectrodic surface gap as ground, the electric field profile was assessed giving as a result the field-modulus distribution represented in Figure 3. For the sake of simplicity, only a plane located at $2 \mu \mathrm{m}$ over the electrode surface is analyzed. It can be seen that points located near to the electrode tips will experience the highest electric field strength, whilst this strength diminishes as the observation point moves towards the central part of the interelectrodic gap, towards the bays or onto the metallic surface of the electrodes. As a result, particles more polarizable than the medium will be collected at the electrode tips. On the other hand, particles less polarizable than the suspending medium will be repelled from the field maxima, clustering at the bay zones or on the electrodes. If $\mathbf{E}$ is represented at higher planes its strength will decay very fast, almost exponentially.

Additionally, a cross-section view of the geometrical inhomogeneity factor $\left(\nabla \mathrm{E}_{\mathrm{RMS}}^{2}\right.$, which is proportional to $\mathbf{F}_{\mathrm{DEP}}$ ) is plotted in Figure 4. For the sake of clarity, magnitude variations in this factor are represented by the color-coded scale instead of the arrows lengths. It can be seen that the highest non-uniformity regions are located around the corners of the electrodes and, as a result of this, the highest value of $\mathbf{F}_{\text {DEP }}$ will be located at these points.

Particles lying in the force field shown in Figure 4 will present p-DEP and will be attracted to and agglomerated at the highest strength region of the electric field if the polarizability function is positive. If particles were oppositely polarized, they would be repelled towards the force field minima as a result of n-DEP.

To sum up, the computer analysis predicts that $\mathrm{p}$ DEP will result in the agglomeration of particles at electrode tips, while n-DEP will cause particles to accumulate on electrode bays and on the electrode surface, as well as in the interelectrodic gap. Of course, the final particle position depends upon the polarizability function value.

One of the most amazing possibilities envisaged for the castellated microelectrodes is that multiple-particle mixtures (two or even more particle types) could be physically separated into different regions, on the basis of their electrical properties. Besides this, an additional force can be used to drag away the desired fraction of particles, collecting them for further assays. However, one must be aware that such a separation involves a careful choice of the experimental conditions, especially the suspending medium conductivity.

\section{The Proposed Microdevice}

The proposed design is a whole microsystem including electrical, optical and fluidic interfaces, as depicted in Figure 5.

The technological process was carried out at the Microelectronics National Center (CNM) in Barcelona, Spain, and can be roughly divided into three stages. The first one is the microelectrode patterning in which platinum electrodes are defined by lift-off onto a silicon wafer of $300 \mu \mathrm{m}$ thickness. After that, the wafer is drilled by bulk silicon micromachining in order to shape the inlet and outlet holes. The wafer-level processing ends up with the photolithographic structuring of an UV-curable polymer to cast the microchamber walls.

As shown in Figure 6, the resulting microelectrode array is actually composed by three microstructures each one formed by classical and shifted interdigitated castellated electrodes, as well as saw-teeth electrodes 

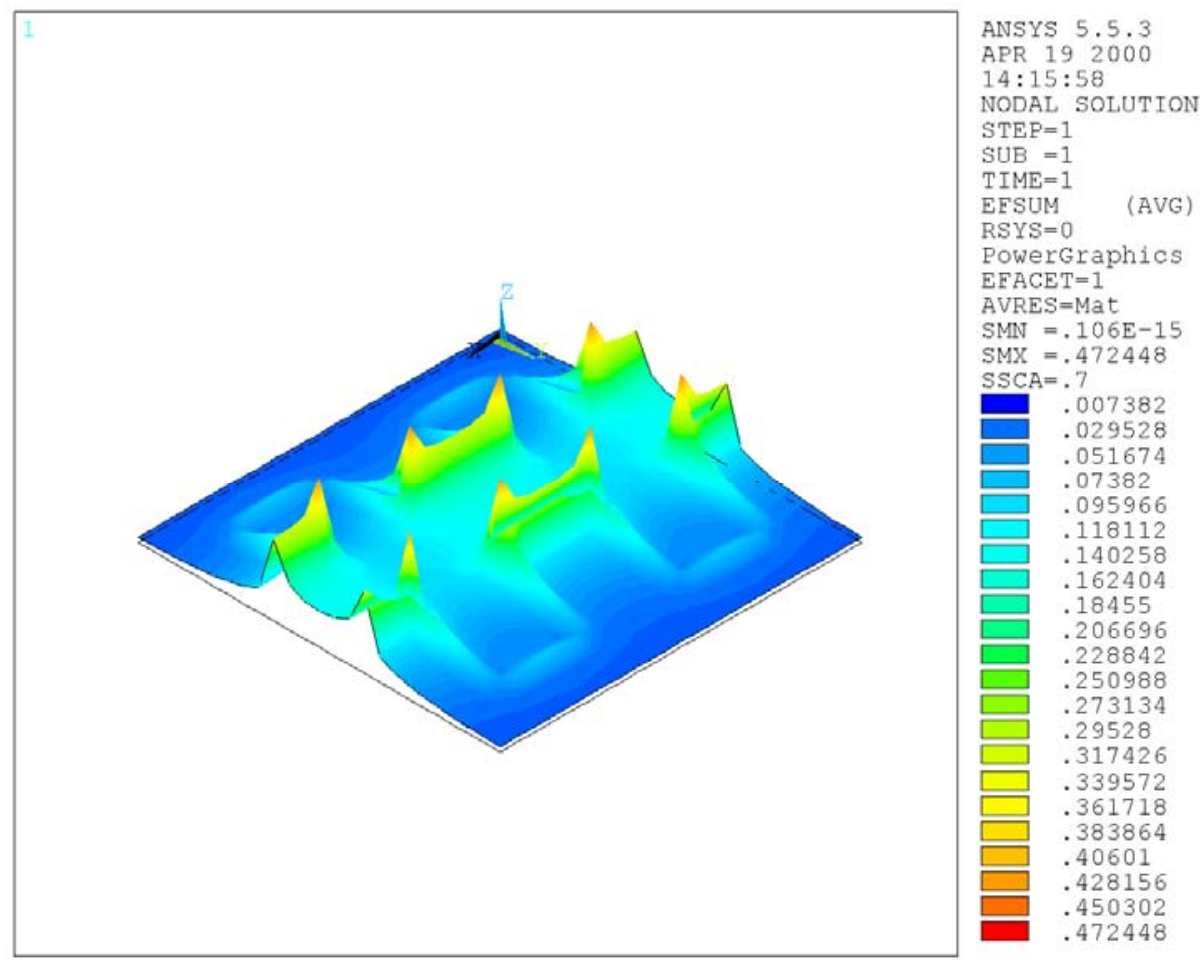

Fig. 3 - Pseudo-topographic representation of the electric field modulus $\left(\mathrm{V}_{\mu \mathrm{m}}^{-1}\right)$ in a plane located at $2 \mu \mathrm{m}$ over the electrode surface.
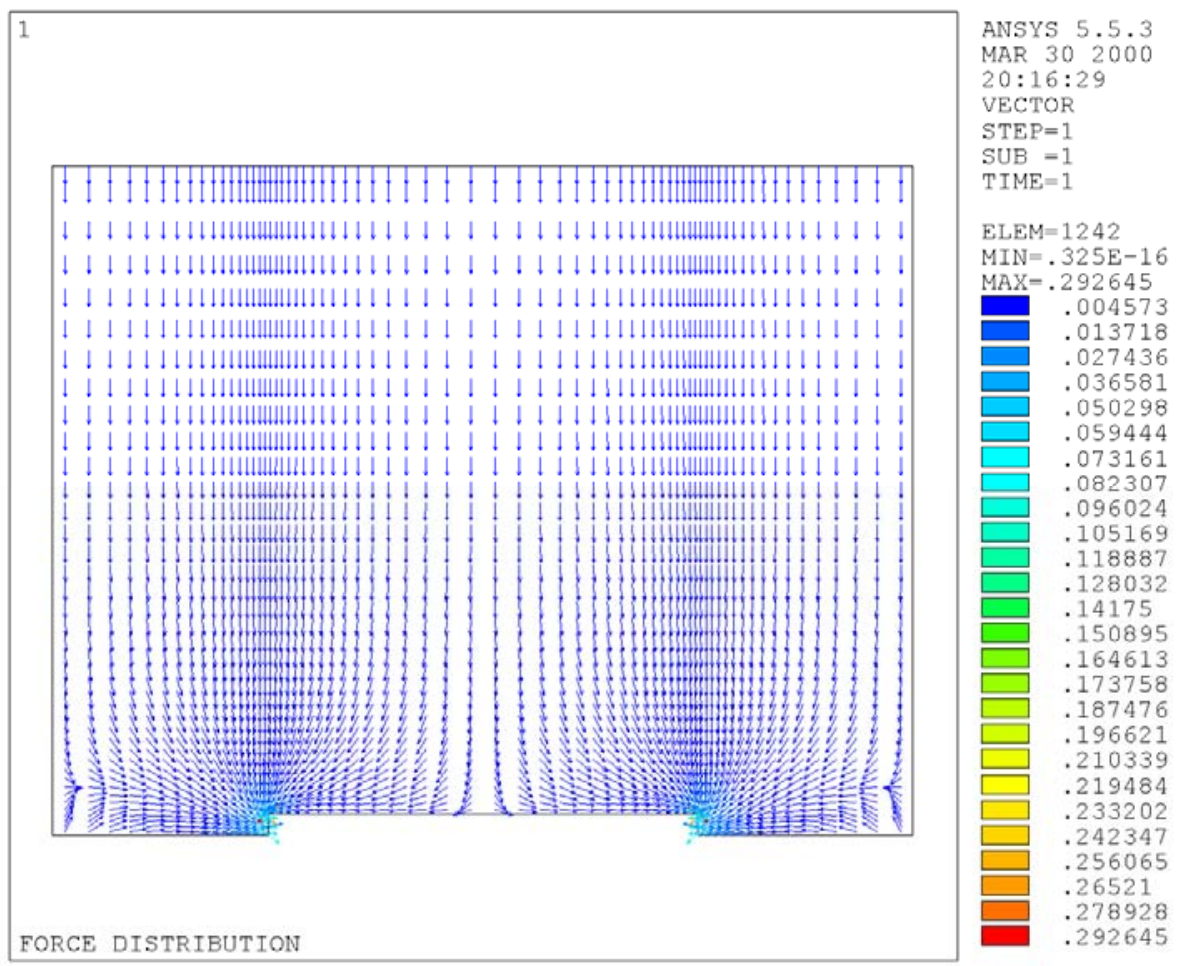

Fig. 4 - Vector representation of the non-uniformity factor $\left(\nabla \mathrm{E}_{\mathrm{RMS}}^{2}\right.$ expressed in $\left.\mathrm{V}^{2} \mu \mathrm{m}^{-3}\right)$, around an electrode tip. 


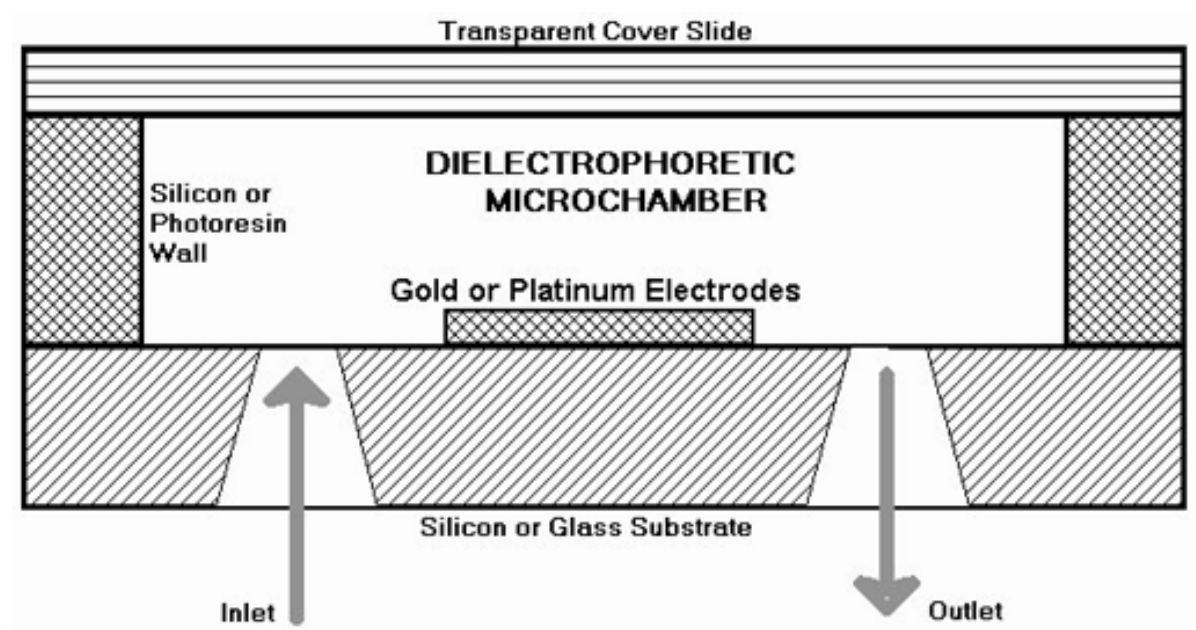

Fig. 5 - Cross-section view of the proposed microdevice. Three main components may be identified: the substrate where electrodes are grown, the electrodes itself responsible for the electric field profiles, and the silicon or photoresin walls limiting the microchamber working area. A couple of holes are drilled to bring the suspending medium onto the electrode surface. A cover slide is placed on the top of the structure to close the cavity.

with typical sizes of 50,70 and $90 \mu \mathrm{m}$ in both electrode length and separation. In order to gain flexibility, electrodes of different size have their own pads for external connection.

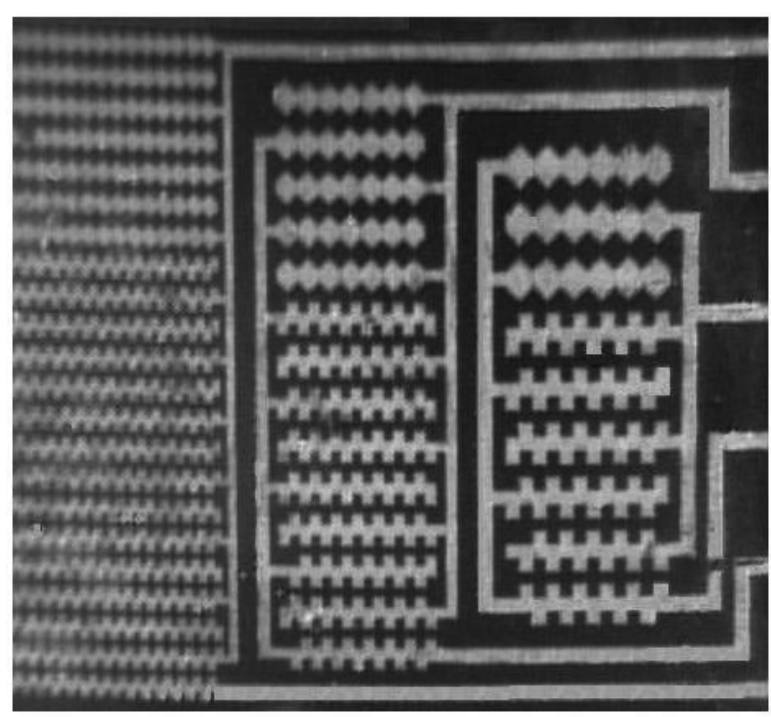

Fig. 6 - Platinum microstructures containing classical and shifted interdigitated castellated, as well as saw-teeth electrode arrays. Magnification $\times 50$.

\section{EXPERIMENTAL SET-UP}

The instrumentation required to perform cell microhandling can be separated into three parts. The first one is the power system that includes a signal generator and an oscilloscope. In this case, the power signal was supplied by a Hewlett Packard 33120 A function generator with amplitude variable between 0 and $10 \mathrm{~V}$ and a frequency range from 0 to $20 \mathrm{MHz}$. The electrical signal calibration was allowed by means of a Tektronix TSD $220,100 \mathrm{MHz}$, two channel digital real-time oscilloscope.

The second part is the particle microhandler itself, which contains the microelectrodes under study. The third part is the optical system that is able to observing and recording the electrokinetic particle behavior. The experimental work was performed employing a stereomicroscope Karl Zeiss SV 11 with a Sony CCD video color camera SSC-370 P, as well as a videotape recorder attached to it. Moreover, there was a color video monitor, Sony KX-1410 QM, connected in parallel to supervise the experiments. Furthermore, taking advantage of a PC provided with a professional quality PCI motion-JPEG card, Aver Media ${ }^{\circledR}$ MV-300, the particle motion behavior could be analyzed digitizing the captured video images and making a frame-by-frame study 
of them. This system is complemented by a cold-light source, which allows light filtering and polarization. Additionally, the liquid medium conductivity was measured by means of a Corning ${ }^{\circledR} 441$ conductivity meter. The whole experimental set-up is placed on an anti-vibration table to reduce the influence of possible external movements when observing the particle electrokinetic behavior (Fernández et al. 2002).

\section{RESULTS}

Having fabricated the microdevice it was ready to demonstrate the major goal of this research: bioparticle microhandling by means of microsystems based on dielectrophoresis. To do this Escherichia coli were used as bioparticle models. They correspond to gramnegative bacterial cells which have been widely studied and their electrical properties are well known (Markx et al. 1994, Brown 1996, Cheng et al. 1998). Results described underneath were obtained employing interdigitated castellated microelectrodes of $70 \mu \mathrm{m}$ in size. Such structures are well-suited to study c-DEP phenomena because they are only driven by two signals inverted in phase.

Gram-negative bacteria (E. coli) were kindly provided by the Microbiology Department of the Barcelona University. All measurements were performed in very low conductivity solutions to reduce the risk of heatingrelated problems. Bioparticles were resuspended in deionized water and the final suspension was adjusted to a concentration of $2 \times 10^{8}$ cells $\mathrm{mL}^{-1}$. The solution conductivity was adjusted between 10 and $20 \mu \mathrm{S} \mathrm{cm}^{-1}$. The shape of these cells is usually tubular with the long dimension varying from submicrometer to about $4 \mu \mathrm{m}$.

Having dropped the bacterial suspension into the micropool, microelectrodes of $70 \mu \mathrm{m}$ were energized with a sinusoidal signal of $10 \mathrm{~V}$ in amplitude and $1 \mathrm{MHz}$. After a few minutes, particles were concentrated forming clusters located at the electrode edges of both classical and shifted interdigitated castellated arrays, i.e. particles were driven towards and agglomerated at regions corresponding to the electric field maxima, as predicted by simulations of the electric field. The aforementioned behavior, i.e. bacteria affected by p-DEP, is illustrated in Figure $7 \mathrm{a}$ where a partial view of the interdigitated castellated microelectrode array can be seen with clus- ters of trapped bioparticles (bright points) onto it. The interelectrodic gap and bays are free of particles, while $E$. coli preferentially agglomerate at the electrode tips as well as at the back-side of the electrode bays.
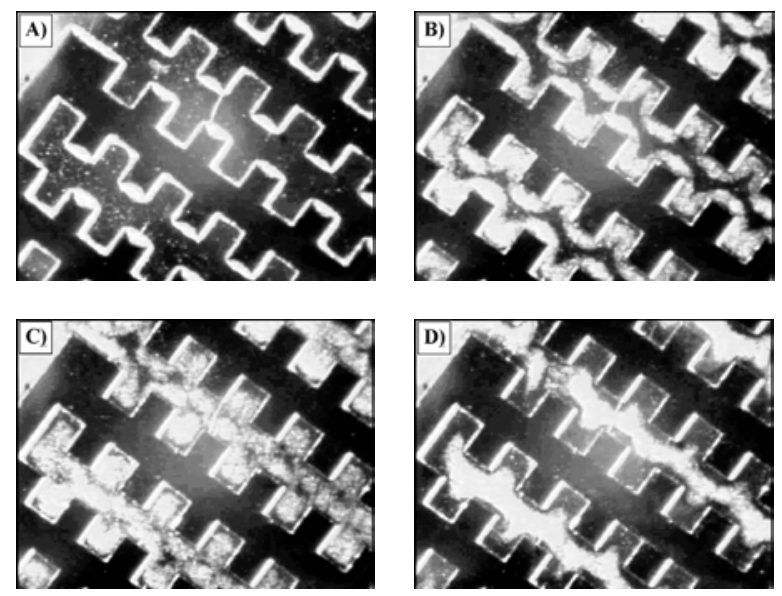

Fig. 7 - Sequence of bacterial movement over the interdigitated castellated microstructure. The applied voltage was $10 \mathrm{~V}$. Frames were captured at: (a) $100 \mathrm{kHz}$, (b) $20 \mathrm{kHz}$, (c) $10 \mathrm{kHz}$, and (d) $1 \mathrm{kHz}$. E. coli were diluted in de-ionized water $\left(\sigma_{m}=10 \mu \mathrm{S} \mathrm{cm}^{-1}\right)$, Magnification $\times 200$.

When the frequency of the applied signal was decreased till approximately $100 \mathrm{kHz}$, maintaining constant the voltage amplitude, bioparticle behavior (i.e. cell motion towards and accumulation at the electrode corners) remained unaltered. The signal frequency was also raised till the highest value allowed by our generating system $(20 \mathrm{MHz})$ but n-DEP could not be verified. In other words, the cell aggregation previously described was observed from $100 \mathrm{kHz}$ to $20 \mathrm{MHz}$, indicating that for our experimental conditions only p-DEP could occur. When the applied signal was switched off, bioparticles were observed to redistribute randomly in the medium as they were prior to applying the electrical signal.

Once bacteria had been collected at the electrode edges under the influence of p-DEP, the applied frequency was reduced below $100 \mathrm{kHz}$ till a value of $1 \mathrm{kHz}$. As the frequency was decreased, particles separated from the electrode edges and moved towards the electrode center, accumulating to form diamond-shaped clusters. When the frequency was raised, bioparticles went back to their initial positions. A sequence of the bioparticle motion is shown in Figure 7. Such a particle behav- 
ior, i.e. particle collection at the center of the electrode surfaces when working at relatively low frequencies in dielectrophoretic-based microdevices, has also been observed by other researchers when working in handling, characterization and separation of microparticles (Green and Morgan 1998, Green et al. 2000a, b).

\section{DISCUSSION}

\section{Positive Dielectrophoresis}

To explain the bioparticle behavior described in Figure $7 \mathrm{a}$, the single-shell particle model was fitted with values corresponding to our experimental choice, i.e. E. coli suspended in de-ionized water of $\sigma_{m}=1 \times$ $10^{-3} \mathrm{~S} \mathrm{~m}^{-1}$ and $\varepsilon_{m}=80$. A plot of the real part of the polarizability function is shown in Figure 8, in which the bioparticle values were taken from the literature (Nishioka et al. 1997, Hughes and Morgan 1999).

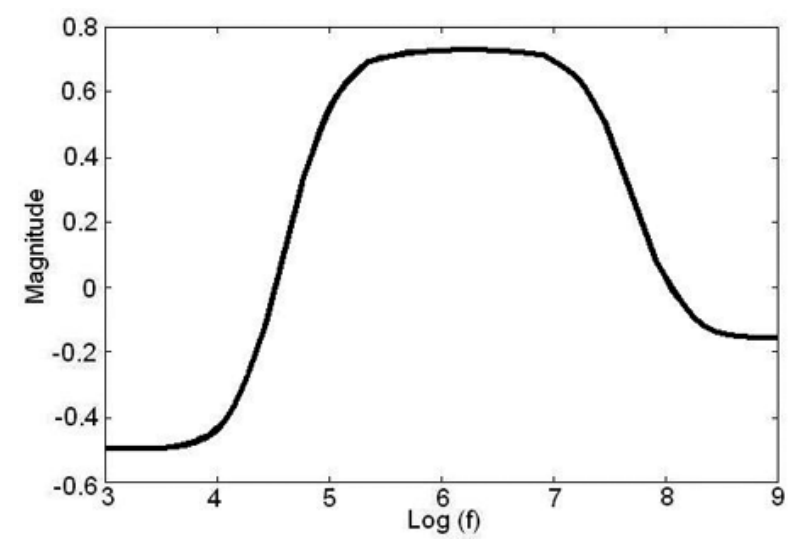

Fig. 8 - Magnitude of $\operatorname{Re}\left[\mathrm{F}_{\mathrm{CM}}\right]$ versus frequency for an $E$. coli of $\varepsilon_{\mathrm{mem}}=3.7, \varepsilon_{\mathrm{int}}=50, \sigma_{\mathrm{mem}}=0 \mu \mathrm{S} \mathrm{m}^{-1}$ and $\sigma_{\text {int }}=0.5 \mathrm{~S} \mathrm{~m}^{-1}$, submersed in de-ionized water of $\sigma_{\mathrm{mem}}=1 \times 10^{-3} \mathrm{~S} \mathrm{~m}^{-1}$. Moreover, $d=10 \mathrm{~nm}$ and $r=2 \mu \mathrm{m}$.

A careful study of Figure 8 reveals that $\mathrm{Re}\left[\mathrm{F}_{\mathrm{CM}}\right]$ has three well-defined behavioral frequency regions. The first one ranges from 1 to about $30 \mathrm{kHz}$, in which n-DEP will occur and is limited by a low-frequency dispersion which gives rise to the first crossover point. The second region ranges from $30 \mathrm{kHz}$ to approximately $100 \mathrm{MHz}$ at which a second crossover point can be seen. A third region, within which n-DEP will occur, ranges at frequencies higher than $100 \mathrm{MHz}$ (where the second dispersion is observed). According to this model, E. coli will be affected by $\mathrm{p}$-DEP for frequencies ranging from
$30 \mathrm{kHz}$ to $100 \mathrm{MHz}$, which is consistent with our experimental observations. On the other hand, Figure 8 shows that to verify n-DEP frequencies lower than $30 \mathrm{kHz}$ or higher than $100 \mathrm{MHz}$ must be applied. However, while the latter range was not available, the former triggered EHD phenomena hindering bioparticles from behaving in the n-DEP regime.

In view of the experimental results one can say that the occurrence of p-DEP in Escherichia coli was successfully experimentally verified. Furthermore, cell behavior is coherent with that described by the particle model corresponding to a single-shell equivalent sphere for frequencies higher than $100 \mathrm{kHz}$.

\section{ELECTROHYDRODYNAMIC EFFECTS}

Since the point of view of 'classical' dielectrophoretic theory, E. coli should remain trapped at the electrode edges for frequencies ranging from $30 \mathrm{kHz}$ to $100 \mathrm{MHz}$ as a result of p-DEP, because the real part of the polarizability function of bacteria is positive in this range. For frequencies below $30 \mathrm{kHz}$, they would be directed toward the electrode bays and interelectrode gaps but such a prediction of the single-shell model could not be verified. On the contrary, it is evident that particles in the interelectrode regions literally jump onto the electrode surface and then move, together with those cells originally on the electrode surface, towards the central region, as shown in Figure 7.

Such a behavior was tentatively attributed to the combination of an electrophoretic effect in aiding cells to cross the electrode boundaries, coupled with a negative dielectrophoretic force in directing them to the center of the electrode surface (Pethig et al. 1992). However, the impressive review of Ramos and co-workers worked out an order-of-magnitude estimation of forces acting in c-DEP microelectrodes, concluding that for the low-frequency range the fluid motion moves particles away from the electrode edge and into well defined regions on top of the electrodes (Ramos et al. 1998).

In fact, the aforementioned review aimed us to perform the numerical analysis of electrohydrodynamic (EHD) effects, i.e. fluid motion as a result of thermally induced medium inhomogeneities, originated on DEPbased microdevices (Fernández 2000). This work demonstrated that at low frequencies, see Figure 9, the fluid 


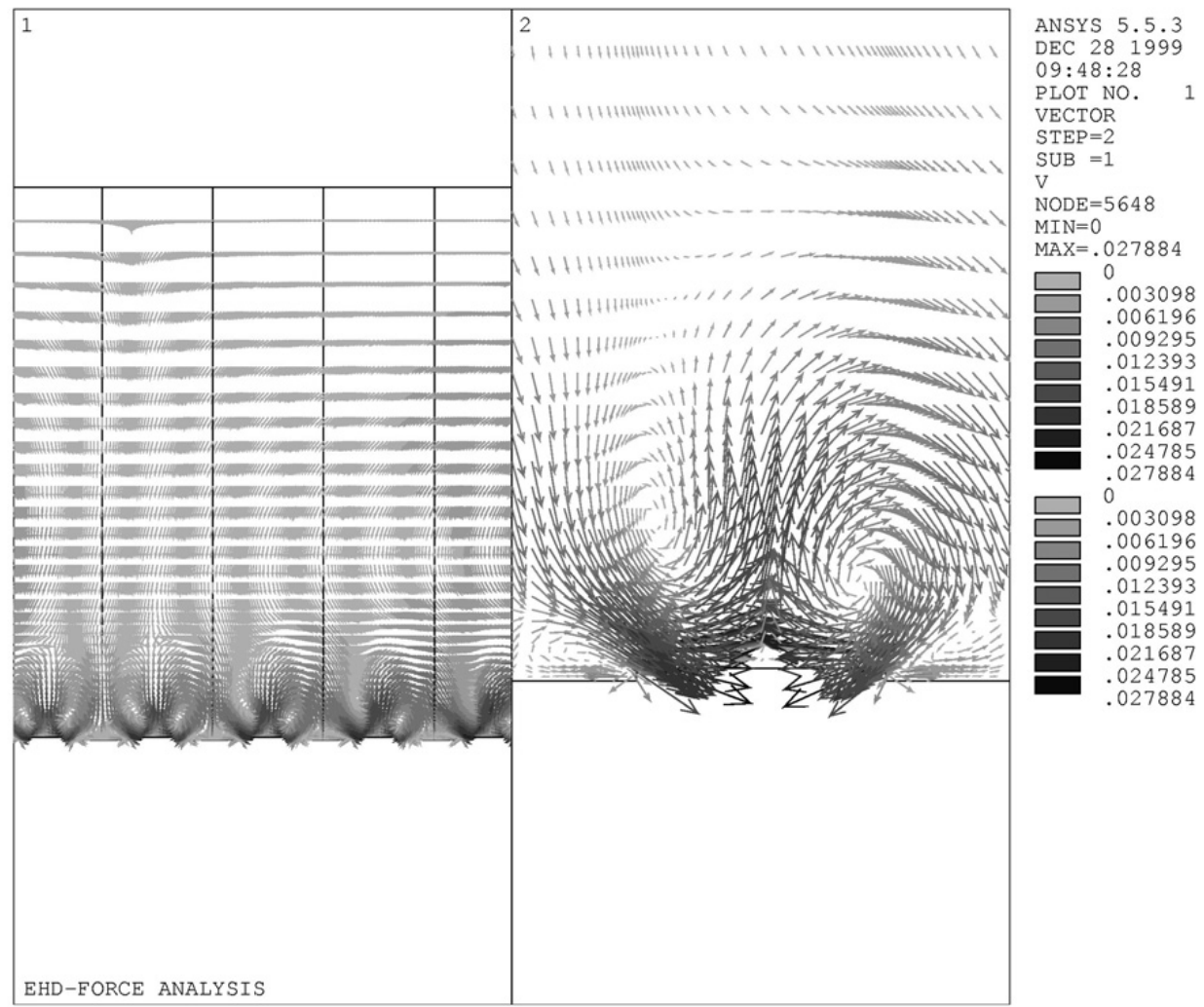

Fig. 9 - Fluid motion behavior at $10 \mathrm{kHz}$, for an interdigitated electrode array modeled by a 2-D FEM model. On the left-side a few electrode domains are shown, while on the right-side a zoom of the neighborhood of an electrode is represented.

motion around the interdigitated microelectrodes consists of a couple of whirlpools rotating in opposite directions; while the left one spins counter-clockwise, the other one rotates clockwise. If there are particles in the solution and the applied voltage is high enough, those particles could show the tendency to concentrate at the center of the electrodes.

Figure 9 shows that particles are drawn down by fluid motion onto the electrode edge and then into the center, where they collect. This effect is dependent on frequency as shown in our experiments with bacterial cells. In view of the practical results, it is evident that other normally unconsidered effects (e.g. EHD and electroosmotic effects), which in addition to the primarily studied dielectrophoretic force also influence the particle motion, must be taken into account when working at low-frequency ranges. Indeed, such a motion actually results as a consequence of the hydrodynamic viscous drag force affecting the particles, which can be originated by EHD effects.

\section{CONCLUSIONS}

This work was conceived to explore the possibilities of microsystems aimed at bioparticle handling based on common dielectrophoresis. To attain this goal, activities were orientated towards the modeling and testing of interdigitated castellated microelectrode arrays which adapt themselves to the electrohandling of both artificial and natural microparticles.

In order to achieve a good understanding of the related phenomena, modeling tasks begin with a description of the electrical model, which includes the particle modeling and the electrical field calculations. A 3-D finite element model was employed to know the electric field profile which is helpful in understanding and predicting the particle behavior. It is worth mentioning that the 3-D approach gives a bit more insight into the electric field shapes than that gained with 2-D models. However, the use of the former rather than the latter will depend on the designer's needs. 
From a technological point of view, a whole microsystem was designed and fabricated by means of microfabrication techniques. Such a microstructure includes a silicon substrate onto which electrodes of platinum were grown by lift-off technique to fulfill biocompatibility requirements.

From the experimental point of view, microstructures were tested utilizing Escherichia coli as bioparticle models. Bacterial cells moved towards the edges of castellated microelectrode arrays and were trapped there, as expected from the electric field calculations, being affected by positive dielectrophoresis when the applied signal was greater than $100 \mathrm{kHz}$. Such bacterial behavior is coherent with that explained by the singleshell particle model but it fails at lower frequencies where predicts the occurrence of negative dielectrophoresis.

As the frequency was decreased, bioparticles were observed to detach from points of maximum electric field strength and move towards the electrode center, clustering there. Nowadays this behavior is attributed to the fluid motion over the electrodes, which moves particles away from the electrode edges and into welldefined regions on top of the electrodes. In fact, numerical calculations of effects, i.e. fluid motion as a result of thermally induced medium inhomogeneities, demonstrated that at low frequencies the fluid motion around the electrodes, consisting of a couple of whirlpools rotating in opposite directions, can detach the particles from the electrode edges dragging them into the center, where they collect.

In view of the practical results, it is evident that other normally unconsidered effects (e.g. EHD and electroosmotic effects), which in addition to the primarily studied dielectrophoretic force also influence the particle motion, must be taken into account when designing and studying DEP-based handling microsystems.

To conclude one can say that the experiments illustrate the convenience of using castellated-platinum microelectrodes to microhandling E. coli, opening the possibility for using them with other kind of bioparticles. Furthermore, viscous drag particle motion as a result of EHD effects must be taken into account and could be used as a mechanism to clean the electrode surfaces, that is one of the most important problems related to biochips.

\section{RESUMO}

Este artigo descreve a modelagem e teste experimental de uma rede de microeletrodos em cremalheira cujo objetivo é o manuseio de células biológicas, com base em dieletroforese comum. O microsistema proposto foi desenvolvido empregando eletrodos de platina depositados por técnicas de 'lift-off', micro-usinagem em silício e litografia com foto-resina. Uma vez fabricado o microdispositivo, este foi testado utilizando a Escherichia coli como modelo de biopartículas. Dieletroforese positiva pode ser observada com as células selecionadas para freqüências acima de $100 \mathrm{kHz}$, e efeitos eletro-hidrodinâmicos foram observados como o fenômeno dominante para menores freqüências. Como resultado, a dieletroforese negativa não pode ser observada pois sua ocorrência se sobrepõe a efeitos eletro-hidrodinâmicos; i.e. a força de arraste viscoso atuando sobre as partículas é superior à força dieletroforética para freqüências em que a dieletroforese negativa deveria ocorrer. Os experimentos ilustram a conveniência deste tipo de micro-dispositivo para o micromanuseio de objetos biológicos, abrindo a possibilidade de uso destas micro-redes com outras partículas biológicas. Além disto, o movimento líquido como resultado dos efeitos eletro-hidrodinâmicos deve ser levado em conta ao se desenhar micromanipuladores de partículas biológicas, e pode ser utilizado como mecanismo para limpar as superfícies dos eletrodos, que é um dos problemas mais importantes relacionados a este tipo de dispositivo.

Palavras-chave: dieletroforese, efeitos eletro-hidrodinâmicos, 'biochips', manuseio de bactérias.

\section{REFERENCES}

ARnOld WM, SchWAN HP AND Zimmermann U. 1987. Surface conductance and other properties of latex particles measured by electrorotation. J Phys Chem 91: 5093-5098.

BROWN AP. 1996. Dielectrophoretic investigations of bacterial cells. Doctoral thesis, University of York, York, United Kingdom.

Burt JPH, Pethig R, Gascoyne PRC AND Becker FF. 1990. Dielectrophoretic characterization of Friend murine erythroleukaemic cells as a measure of induced differentiation. Biochim Biophys Acta 1034: 93-101.

Cheng J, Sheldon E, Wu L, Uribe A, Gerrue L, CarRino J, Heller M ANd O'Connell J. 1998. Preparation and hibridization analysis of DNA/RNA from $E$. coli on microfabricated bioelectronic chips. Nat Biotechnol 16: 541-546. 
Choi JW, Bhansali S, Ahn C and Thurman H. 1999. A new magnetic bead-based filterless bio-separator for integrated bio-molecule detection systems. The 13th European Conference on Solid-State Transducers EUROSENSORS XIII, The Hague, The Netherlands, September $12-15$, p. 363-364.

FEELEY CM AND PoHL HA. 1981. The influence of resistivity and permittivity on the motion of uncharged solid particles in non-uniform electric fields (the 'dielectrophoretic effect'). J Phys D Appl Phys 14: 2129-2138.

FERNÁNDEZ F. 2000. Design, assembly and testing of microsystems for dielectrophoresis-based bioparticle electrohandling. Doctoral thesis, Department of Electronics, University of Barcelona, Barcelona, Spain.

Fernández FH, DuARte JE AND SAmitier J. 2002. Micro-belt conveyor of latex microspheres. 17th Symposium on Microelectronics Technology and Devices, SBMicro, Porto Alegre, Brazil, September 9-14, p. 133-140.

Figeys D AND Pinto D. 2000. Lab-on-a-chip: A revolution in biological and medical and medical sciences. Anal Chem 72: 330a-335a.

FUHR G AND SHIRLEY SG. 1998. Biological application of microstructures. Top curren chem 194: 83-116.

FUHR G AND WAGNER B. 1994. Electric field mediated cell manipulation in highly conductive culture media. Microsystem technologies '94/4th International Conference on Micro, Electro, Opto, Mechanical Systems and Components, Berlin, Germany, p. 407-416.

Fuhr G, Schnelle T, Müller T, Hitzler H, MonaJEMBASHI S AND GREUliCH K. 1998a. Force measurements of optical tweezers in electro-optical cages. Appl Phys A 67: 385-390.

Fuhr G, MÜller T, BAukloh V AND LuCAs K. 1998b. High-frequency electric field trapping of individual human spermatozoa. Hum Reprod 13: 136-141.

GASCOYNE PRC, BECKER FF AND WANG XB. 1995. Numerical analysis of the influence of experimental conditions on the accuracy of dielectric parameters derived from electrorotation measurements. Bioelectrochem Bioenerg 36: $115-125$.

GASCOYNE PRC, WANG XB, HuANG Y AND BECKER FF. 1997. Dielectrophoretic separation of cancer cells from blood. IEEE Trans Ind Appl 33: 670-678.

Green NG AND Morgan H. 1998. Separation of submicrometre particles using a combination of dielectrophoretic and electrohydrodynamic forces. J Phys D Appl Phys 31: L25-L30.

Green NG, Ramos A And Morgan H. 2000a. Ac elec- trokinetics: a survey of sub-micrometre particle dynamics. J Phys D Appl Phys 33: 632-641.

Green NG, RAmos A AND GonZÁlez A. 2000b. Electric field induced fluid flow motion on microelectrodes; the effect of illumination. J Phys D Appl Phys 33: L13-L17.

Hoettges K, Hughes M, Cotton A, Hopkins N And MCDONELL M. 2003. Optimizing particle collection for enhanced surface-based biosensors. IEEE Eng Med Biol Mag 22: 68-74.

Hughes MP ANd Morgan H. 1999. Measurement of flagellar bacterial thrust by negative dielectrophoresis. Biotech Prog 15: 245-249.

Kaler K AND POHL HA. 1983. Dynamic dielectrophoretic levitation of living individual cells. IEEE Trans Ind Appl IA-19: 1089-1093.

KoHnKE P. 1995. ANSYS Theory Reference Manual release 5.5. Swanson Analysis Systems Inc.

LeE SW And TaI YC. 1999. A micro cell lysis device. Sens Actuators A 73: 74-79.

LEE SW, ChOI JH AND KIM YK. 1995. Design of a biological cell fusion device. The 8th International Conference on Solid-State Sensors and Actuators, and Eurosensors IX. TRANSDUCERS'95 - EUROSENSORS IX, Stockholm, Sweden, June 25-29, p. 377-380.

Markx GH, Huang Y, Zhou XF and Pethig R. 1994. Dielectrophoretic characterization and separation of micro-organisms. Microbiology 140: 585-591.

Nishioka M, Katsura S, Hirano K and Mizuno A. 1997. Evaluations of cell characteristics by step-wise orientational rotation using optoelectrostatic micromanipulation. IEEE Trans Ind Appl 33: 1381-1388.

Pethig R, HuAng Y, Wang XB ANd Burt JPH. 1992. Positive and negative dielectrophoretic collection of colloidal particles using interdigitated castellated microelectrodes. J Phys D Appl Phys 24: 881-888.

Pethig R, Burt JPH, Parton A, Rizvi N, Talary MS AND TAME JA. 1998. Development of biofactory-on-achip technology using excimer laser micromachining. J Micromech Microeng 14: 57-63.

POHL HA. 1951. The motion and precipitation of suspendoids in divergent electric fields. J Appl Phys 22: 869-871.

Porras YM, PEDraza OA, FERnÁNDEZ FH AND DUARTE JE. 2004. Manipulación de protozoos por ultrasonido. Rev Col Biotecn 6: 79-84.

Ramos A, Morgan H, Green NG And Castellanos A. 1998. Ac electrokinetics: a review of forces in microelectrodes structures. J Phys D Appl Phys 31: 2338-2353. 
Reimer K, Köhler C, Lisec T, Schnakenberg U, Fuhr G, Hintsche R AND WAGner B. 1995. Fabrication of electrode arrays in the quarter micron regime for biotecnological applications. Sens Actuators A 46-47: 66-70.

Rosenthel A And Voldman J. 2005. Dielectrophoretic traps for single-particle patterning. Biophys J 88: $2193-$ 2205.

SATO K, KaWAmura Y, TANAKa S, UChida K AND KoHIDA H. 1990. Individual and mass operation of biological cells using micromechanical silicon devices. Sens Actuators A21-A23: 948-953.

Schnelle $\mathrm{T}$, Müller $\mathrm{T}$, Voigt A, Reimer $\mathrm{K}$, WAGNer B AND FuHR G. 1996. Adhesion-Inhibited surfaces. Coated and uncoated interdigitated electrode arrays in the micrometer and submicrometer range. Langmuir 12: 801-809.

Stephens M, Talary M, Pethig R, Burnett A and MILLS K. 1996. The dielectrophoresis enrichment of CD34+ cells from peripheral blood stem cell harvests. Bone Marrow Transpl 18: 777-782.
VELEV O AND KALER E. 1999. In situ assembly of colloidal particles into miniaturized biosensors. Langmuir 15: 3693-3698.

WANG XB, HUANG Y, BURT JPH, MARKX GH AND Pethig R. 1993. Selective dielectrophoretic confinement of bioparticles in potential energy wells. J Phys D Appl Phys 26: 1278-1285.

WANG XB, HuAng Y, Gascoyne PRC AND BeCKer FF. 1997. Dielectrophoretic manipulation of particles. IEEE Trans Ind Appl 33: 660-669.

Webster JR And Mastrangelo CH. 1997. Large-volume integrated capillary electrophoresis stage fabricated using micromachining of plastics on silicon substrates. International Conference on Solid-State Sensors and Actuators TRANSDUCERS'97, Chicago, Illinois, USA, June 16-19, 503-506. 